\title{
Ocena przydatności komercyjnych elektrod otulonych do spawania mokrego pod wodą z wykorzystaniem analizy skupień
}

\author{
Evaluation of usefulness of commercial covered electrodes \\ for wet underwater welding with the use of cluster analysis
}

\section{Streszczenie}

Najbardziej uniwersalną i ekonomiczną metodą remontów konstrukcji eksploatowanych pod wodą jest spawanie mokre elektrodami otulonymi. Ze względu na bardzo dobrą operatywność i stabilność jarzenia się łuku w środowisku wodnym stosuje się elektrody o otulinie rutylowej. Na rynku dostępnych jest kilka gatunków elektrod dedykowanych do prac podwodnych, których cena jest znacznie wyższa niż elektrod komercyjnych. Celem pracy było statystyczne zbadanie możliwości zastąpienia droższych elektrod specjalistycznych popularnymi zamiennikami. Na podstawie danych zgromadzonych z katalogów producentów materiałów dodatkowych do spawania i przy zastosowaniu technik analizy skupień (metody Warda i k-średnich) określono względne podobieństwo 37 gatunków elektrod rutylowych. Zastosowana metodologia pozwoliła na wytypowanie spośród analizowanych elektrod gatunków najbardziej zbliżonych pod względem składu chemicznego i własności stopiwa do elektrod przeznaczonych do prac podwodnych.

Słowa kluczowe: spawanie pod wodą, spawanie mokre, elektrody otulone, analiza skupień

\section{Abstract}

The most versatile and economical method of repair of underwater constructions is wet welding with coated electrodes. Due to the very good operability and stability of arc in a water environment electrodes with rutile coating are used. On the market there are several types of electrodes dedicated for underwater welding, whose price is much higher than commercial electrodes. The aim of this study was to statistically investigate the possibility of replacing expensive specialized electrodes with conventional alternatives. On the basis of data collected from manufacturers' catalogues of consumables and by applying cluster analysis techniques (Ward and k-means methods), the relative similarity of 37 types of rutile electrodes was determined. The applied methodology allowed to nominate electrodes among the analysed types, which are most similar in chemical composition and properties of the weld metal to the electrodes designed for underwater works.

Keywords: underwater welding, wet welding, covered electrodes, cluster analysis

\section{Wstęp}

Spawanie pod wodą jest tańszą alternatywą dla napraw jednostek pływających i konstrukcji hydro- i oceanotechnicznych, ponieważ nie wymaga ich wynurzania nad powierzchnię wody. Jednak spawanie podwodne prowadzone jest w warunkach dużych prędkości stygnięcia złączy, silnego nasycenia jeziorka gazami, ograniczonej widzialności, podwyższonego ciśnienia i mniejszej stabilności jarzenia się łuku, co negatywnie wpływa na spawalność stali. Poważne utrudnienie stanowi również utrudniona operatywność oraz ograniczona możliwość przeprowadzania zabiegów technologicznych: podgrzewania wstępnego, szlifowania, przekuwania i obróbki cieplnej po spawaniu. Niekorzystny wpływ wody na własności złączy najsilniej ujawnia się podczas spawania mokrego, podczas którego obszar spawania

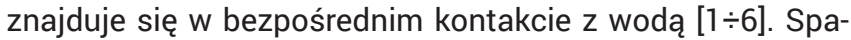
wanie $\mathrm{w}$ warunkach mokrych realizowane jest $\mathrm{w}$ praktyce tylko metodami 111 i 114, stąd większość doniesień literaturowych związanych z rozwojem materiałów dodatkowych do spawania dotyczy elektrod otulonych i drutów proszko-

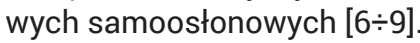

Do spawania mokrego pod wodą stali wykorzystuje się elektrody ferrytyczne oraz austenityczne o otulinie rutylowej albo (znacznie rzadziej) utleniającej $[2,4,6,10]$. Wynika to z lepszej stabilności jarzenia się łuku niż przy zastosowaniu elektrod zasadowych [11]. Przeznaczone do spawania pod wodą elektrody otulone są fabrycznie pokryte dodatkową powłoką wodoodporną. Jej zadaniem jest ograniczenie nasiąkliwości otuliny przy jednoczesnym umożliwieniu

Dr inż. Dariusz Fydrych, dr inż. Grzegorz Rogalski, mgr inż. Aleksandra Świerczyńska, dr hab. inż. Jerzy Łabanowski, prof. nadzw. PG - Politechnika Gdańska. 
łatwego zajarzenia łuku i zachowaniu stabilności procesu. Na rysunku 1 pokazano rutylowe elektrody o średnicy $4 \mathrm{~mm}$ do spawania pod wodą i na powietrzu.
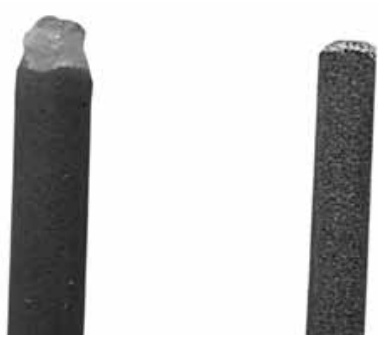

Rys. 1. Widok elektrod otulonych: a) elektroda do spawania pod wodą z powłoką wodoodporną; b) standardowa elektroda rutylowa Fig. 1. View of coated electrodes: a) waterproofed electrode for underwater welding; b) standard rutile electrode

Główne kierunki rozwoju elektrod otulonych dotyczą modyfikacji składu chemicznego otuliny, rdzenia oraz powłoki wodoodpornej $[6,12 \div 16]$. Zmiany składu chemicznego otulin mają za zadanie poprawę własności jonizacyjnych otuliny w celu zmniejszenia wpływu głębokości (ciśnienia wody) na stabilność łuku oraz minimalizację ilości wodoru dyfundującego w złączu $[6,12]$. Wprowadzanie do rdzenia elektrody dodatków stopowych (Ni, Mo) służy ograniczeniu skłonności do pękania krystalizacyjnego i kruchego spoin $[13,14]$. Przedmiotem badań była również możliwość wykorzystania różnych substancji do wykonywania powłok wodoodpornych $[15,16]$. Osobne prace prowadzone były nad modyfikacją budowy elektrod (elektrody wielowarstwowe i z osiowym otworem na gaz) [17]. Obecnie na rynku materiałów spawalniczych dostępnych jest kilka gatunków elektrod dedykowanych do prac podwodnych różniących się składem chemicznym rdzenia, otuliny i powłoki wodoodpornej, jednak ich cena jest znacznie (kilkanaście razy) wyższa niż elektrod komercyjnych.

Analiza skupień stanowi zbiór metod statystycznych wykorzystywanych do klasyfikacji i porównywania obiektów wielowymiarowych, tzn. charakteryzowanych przez wiele cech diagnostycznych $[18 \div 21]$. Celem stosowania analizy skupień jest podział obiektów na możliwie jednorodne skupienia, przy czym obiekty należące do tego samego skupienia powinny być do siebie maksymalnie podobne, natomiast elementy z różnych skupień powinny różnić się w jak największym stopniu. W zależności od metody podziału elementów na grupy, techniki analizy skupień można podzielić na hierarchiczne i niehierarchiczne. Algorytmy postępowania

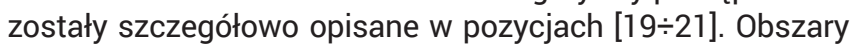
zastosowania analizy skupień obejmują wszystkie dziedziny nauk humanistycznych, ścisłych, społecznych, przyrodniczych, medycznych, ekonomicznych, itd. [18-28]. Wiele metod zostało zaimplementowanych w popularnych pakietach statystycznych, np.: Statistica, Statgraphic, R [20,21].

\section{Badania własne}

Celem pracy było statystyczne zbadanie możliwości zastąpienia droższych elektrod specjalistycznych popularnymi zamiennikami.

Zakres pracy przewidywał realizację następujących działań:

1) Zgromadzenie danych do analiz statystycznych i wybór cech diagnostycznych,

2) Przygotowanie (weryfikacja korelacyjna, analiza zmienności, normalizacja i stymulacja) danych,

3) Analiza metodą hierarchiczną (Warda z odległością euklidesową),
4) Analiza metodą niehierarchiczną (k-średnich z wstępnymi centrami skupień wg opcji: sortuj odległości i weź obserwacje przy stałym interwale),

5) Interpretacja i weryfikacja merytoryczna wyników analiz. Dane do analiz pozyskano z katalogów 7 producentów materiałów dodatkowych do spawania. Zbiór 7 potencjalnych cech diagnostycznych wytypowano na podstawie analizy charakterystyk 37 rutylowych elektrod otulonych podawanych przez producentów. Zaliczono do niego skład chemiczny: zawartość $\mathrm{C}, \mathrm{Mn}, \mathrm{Si}$ oraz własności wytrzymałościowe: Re, Rm, A i KV stopiwa elektrod. W wyniku weryfikacji korelacyjnej usunięto ze zbioru cech diagnostycznych $\mathrm{Rm}$. Na tym etapie analiz nie stwierdzono istnienia istotnych korelacji miedzy cechami diagnostycznymi.

Specyfika zagadnienia wpłynęła na konieczność przyjęcia podczas doboru cech diagnostycznych i przygotowywania danych kilku istotnych założeń. Z powodu braku kompletnych danych analizy przeprowadzono z pominięciem wydłużenia A i zawartości Ni w stopiwie elektrod. Analiza skupień jest wrażliwa na istnienie punktów odstających, więc w rozważaniach nie uwzględniono ceny jako cechy dyskryminującej, ponieważ jest ona znacznie wyższa w przypadku elektrod do spawania pod wodą. Pominięto również udarność stopiwa, ponieważ wartości podane w materiałach producentów zostały uzyskane w różnych temperaturach. Ostatecznie analizy przeprowadzono dla cech: zawartość C, Mn, Si oraz granica plastyczności Re. Wszystkie cechy diagnostyczne charakteryzowała odpowiednia zmienność $(\omega>0,1)$. Ponieważ przyjęto, że wszystkie cechy są stymulantami zostały one znormalizowane wg zależności [18]:

$$
x_{i j}^{\prime}=\frac{x_{i j}-\min \left\{x_{i j}\right\}}{\max \left\{x_{i j}\right\}-\min \left\{x_{i j}\right\}}
$$

Elektrody tradycyjne oznaczono literą oznaczającą producenta oraz numerem kolejnym, natomiast elektrody do spawania pod wodą oznaczono symbolem UW i numerem kolejnym. Cechy $\mathrm{z}$ wartościami znormalizowanymi oznaczono indeksem n.

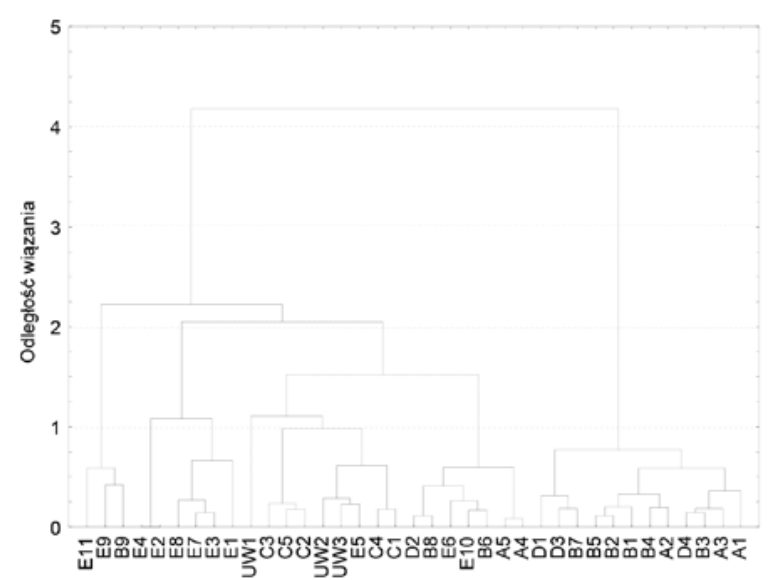

Rys. 2. Dendrogram klasyfikacji rutylowych elektrod otulonych metodą Warda $z$ odległością euklidesową

Fig. 2. Euclidean distance dendrogram (Ward method) of rutile coated electrodes

Analizy statystyczne zbioru danych, którego fragment pokazano w tablicy I, zrealizowano w programie Statistica [20] w dwóch etapach. W pierwszym przeprowadzono analizy metodą Warda z odległością euklidesową, natomiast w drugim zastosowano metodę k-średnich z opcją: sortuj odległości i weź obserwacje przy stałym interwale. Na rysunku 1 pokazano dendrogram opracowany metodą Warda, natomiast na rysunku 2 wykres liniowy k-średnich. Korzystając z metody wykresu odległości wiązania względem wiązania, elektrody podzielono na trzy skupienia. 
Tablica I. Fragment zbioru ze znormalizowanymi danymi wejściowymi do analiz statystycznych

Table I. Part of the collection of the normalized input data for statistical analysis

\begin{tabular}{|c|c|c|c|c|c|c|c|}
\hline Kod & Cn & Mnn & Sin & Ren & Rmn & A5n & KVn \\
\hline A1 & 0,714 & 0,308 & 0,322 & 0,118 & 0,231 & 0 & 0,386 \\
\hline A2 & 0,429 & 0,545 & 0,322 & 0,118 & 0,231 & 0 & 0,386 \\
\hline B1 & 0,429 & 0,364 & 0,322 & 0 & 0 & 0,250 & 0,429 \\
\hline B2 & 0,429 & 0,364 & 0,322 & 0,118 & 0,308 & 0,250 & 0,571 \\
\hline D1 & 0,429 & 0 & 0,322 & 0,118 & 0,231 & 0 & 0,386 \\
\hline D2 & 0,571 & 0,364 & 0,661 & 0,353 & 0,462 & 0,750 & 0,571 \\
\hline D3 & 0,286 & 0,182 & 0,492 & 0,118 & 0,231 & 0,250 & 0,500 \\
\hline E1 & 1 & 0,364 & 1 & 0,647 & 0,846 & 0,375 & 0,514 \\
\hline E11 & 0,286 & 1,091 & 1 & 0,529 & 1 & 0,750 & 0,714 \\
\hline UW1 & 0 & 0 & 0 & 1 & 0,769 & bd & bd \\
\hline UW2 & 0,143 & 0,436 & 0,576 & 0,647 & 0,615 & bd & bd \\
\hline UW3 & 0 & 0,364 & 0,746 & 0,588 & 0,769 & 0,750 & 0,600 \\
\hline bd - brak danych & & & & & \\
\hline
\end{tabular}

0,9

0,8

0,7

0,6

0,5

0,4

0,3

\begin{tabular}{l|lll}
0,2 & & & $\begin{array}{r}\text { Skupienie 1 } \\
\text { Skupienie 2 } \\
\text { Skupienie 3 }\end{array}$ \\
\hline Cn & & & Ren \\
\hline & Mnn Zmienne & Sin &
\end{tabular}

Rys. 3. Wykres liniowy k-średnich dla skupień rutylowych elektrod otulonych

Fig. 3. K-means plot for clusters of rutile coated electrodes
Tablica II. Wyniki grupowania rutylowych elektrod otulonych metodą k-średnich

Table II. Results of grouping of rutile coated electrodes obtained using k-means method

\begin{tabular}{|c|c|c|}
\hline $\begin{array}{c}\text { Numer } \\
\text { skupienia }\end{array}$ & Elementy skupienia & Opis skupienia \\
\hline \multirow{2}{*}{1} & $\begin{array}{c}\mathrm{A} 1, \mathrm{~A} 2, \mathrm{~A} 3, \mathrm{~B} 1, \mathrm{~B} 2, \\
\mathrm{~B} 3, \mathrm{~B} 4, \mathrm{~B} 5, \mathrm{~B} 7, \mathrm{C1}, \\
\mathrm{C} 2, \mathrm{C}, \mathrm{C} 4, \mathrm{C} 5, \mathrm{D} 1, \\
\mathrm{D} 2, \mathrm{D} 3, \mathrm{D} 4, \mathrm{E} 6, \mathrm{UW} 1\end{array}$ & $\begin{array}{c}\text { Niska zawartość pier- } \\
\text { wiastków stopowych } \\
\text { i wartość granicy pla- } \\
\text { styczności }\end{array}$ \\
\hline \multirow{2}{*}{2} & $\begin{array}{c}\text { A4, A5, B9, E5, E9, } \\
\text { E11, UW2, UW3 }\end{array}$ & $\begin{array}{c}\text { Niska zawartość C, } \\
\text { wysoka zawartość Mn } \\
\text { i Si, przeciętna wartość } \\
\text { granicy plastyczności }\end{array}$ \\
\hline 3 & B6, B8, E1, E2, E3, & $\begin{array}{c}\text { Przeciętna zawartość } \\
\text { Mn, wysoka zawartość } \\
\text { C, Si i wartość granicy } \\
\text { plastyczności }\end{array}$ \\
\hline
\end{tabular}

\section{Podsumowanie}

Woda jako środowisko spawania jest przyczyną wielu istotnych zagrożeń obniżających spawalność metali: zwiększonej prędkości stygnięcia, nawodorowania stopiwa oraz (zależnie od głębokości realizowania prac) wpływu ciśnienia, jednak duży popyt na realizacje prac spawalniczych pod wodą wymusza wielokierunkowy rozwój związanych z nimi technologii.

Przeprowadzono grupowanie metodami analizy skupień (Warda i k-średnich) 37 rutylowych elektrod otulonych do spawania po powietrzu i pod wodą oferowanych przez 7 producentów. Zgodnie z kryteriami taksonomicznymi zbiór analizowanych materiałów dodatkowych został podzielony na trzy skupienia obiektów o rożnej charakterystyce (tablica II). Zastosowana metodologia pozwoliła na wytypowanie spośród analizowanych elektrod gatunków najbardziej zbliżonych pod względem składu chemicznego i własności stopiwa (granicy plastyczności) do elektrod przeznaczonych do prac podwodnych. W przypadku analizowanego zestawu gatunków elektrod najbardziej zbliżona do elektrody UW3 pod względem przyjętych kryteriów klasyfikacji jest elektroda E5, a w dalszej kolejności UW2, C1 i C4 (rys. 2). Natomiast dla elektrody UW3 rolę zamiennika mogą pełnić elektrody od producenta C oraz gatunki UW1, UW2 i E5. Należy podkreślić, że wyniki analiz dotyczą tylko rozpatrywanego zestawu gatunków elektrod, obarczone są błędami wynikającymi z przyjętych założeń i nie uwzględniają czynników, które mogą stanowić istotne kryteria doboru spoiw, np.: łatwości zajarzania i stabilności łuku, dostępności elektrod, czy subiektywnych preferencji i własnych doświadczeń. Dodatkowym czynnikiem ograniczającym zastosowanie zaproponowanej metody wyszukiwania zamienników jest konieczność pozyskania obiektywnych, jednorodnych i kompletnych danych opisujących materiały dodatkowe do spawania. 


\section{Literatura}

[1] Zhang H.T., Dai X.Y., Feng J.C., Hu L.L.: Preliminary investigation on real-time induction heating-assisted underwater wet welding. Welding Journal 1/2015.

[2] Fydrych D., Rogalski G, Łabanowski J.: Problems of underwater welding of higher-strength low alloy steels. Institute of Welding Bulletin $5 / 2014$.

[3] Fydrych D., Łabanowski J., Rogalski G.: Weldability of high strength steels in wet welding conditions. Polish Maritime Research 2/2013.

[4] Guo N., Yang Z., Wang M., Yuan X., Feng J.: Microstructure and mechanical properties of an underwater wet welded dissimilar ferritic/ austenitic steel joint. Strength of Materials 1/2015.

[5] Gao W., Wang D., Cheng F., Deng C., Liu Y., Xu W.: Enhancement of the fatigue strength of underwater wet welds by grinding and ultrasonic impact treatment. Journal of Materials Processing Technology $223 / 2015$.

[6] Santos V.R., Monteiro M.J., Rizzo F.C., Bracarense A.Q., Pessoa E.C.P., Marinho R.R. Vieira L.A.: Development of an oxyrutile electrode for wet welding. Welding Journal 12/2012.

[7] Jia C., Zhang T., Maksimov S.Y., Yuan X.: Spectroscopic analysis of the arc plasma of underwater wet flux-cored arc welding. Journal of Materials Processing Technology 213/2013.

[8] Guo N., Xu C., Guo W., Du Y., Feng J.: Characterization of spatter in underwater wet welding by $\mathrm{X}$-ray transmission method. Materials \& Design 85/2015

[9] Guo N., Wang M., Du Y., Guo W., Feng J.: Metal transfer in underwater fluxcored wire wet welding at shallow water depth. Materials Letters 144/2015.

[10] Bracarense A.Q., Pessoa E.C., Santos V.R.D., et al.: Comparative study of commercial electrodes for underwater wet welding. Soldagem \& Inspeção 4/2010.

[11] Pessoa E.C., Ribeiro L.F., Bracarense A.Q, et al: Arc stability indexes evaluation on underwater wet welding. In ASME 29th International Conference on Ocean, Offshore and Arctic Engineering. American Society of Mechanical Engineers 2010.

[12] Chen W.J., Gui C.B., Sun J.: Preparation of water-resistant electrode coating with palmitic acid by microwave reaction. Advanced Materials Research 228-229/2011.

[13] Silva L.F., Santos V.R.D., Paciornik S., et al.: Influence of molybdenum in metal weld properties in welding wet with oxy-rutillic electrodes. Soldagem \& Inspeção 2/2013.

[14] Guo N., Liu D., Gu W., Li H., Feng J.: Effect of Ni on microstructure and mechanical properties of underwater wet welding joint. Materials \& Design $77 / 2015$
[15] Perdomo-González L., Bracarense A., Quintana-Puchol R., Caires Pereira E., Rodríguez Pérez M., Duffus Scott, A.: Perspective of use of expanded polystyrene as an alternative waterproof coating for electrodes used in underwater wet welding. Revista Facultad de Ingeniería Universidad de Antioquia 62/2012.

[16] Rodríguez-Pérez M., Bracarense A., Perdomo-González L., QuintanaPuchol R. Duffus-Scott A.: Evaluación de diferentes tipos de barnices en la protección de electrodos para la soldadura subacuática. Ingeniería Mecánica 2/2012.

[17] Bracarense A.Q., González L.P., Pessoa E.C.P., Puchol R.Q.: Development of tubular coated electrodes for underwater wet welding. Revista Técnica de la Facultad de Ingeniería 2/2010.

[18] Młodak A.: Analiza taksonomiczna w statystyce regionalnej. Centrum Doradztwa i Informacji Difin, Warszawa 2006.

[19] Krzyśko M., Wołyński W., Górecki T., Skorzybut M.: Systemy uczące się. Rozpoznawanie wzorców, analiza skupień i redukcja wymiarowości. WNT, Warszawa 2008

[20] Stanisz A.: Przystępny kurs statystyki z zastosowaniem STATISTICA PL na przykładach z medycyny. Tom 3. Analizy wielowymiarowe. Wydawnictwo Statsoft Polska, Kraków 2007.

[21] Gatnar E., Walesiak M.: Statystyczna analiza danych z wykorzystaniem programu R. PWN, Warszawa 2009.

[22] Fydrych D., Sommer S., Rogalski G.: Wspomaganie decyzji zakupu urządzeń do spawania metodą MIG/MAG z wykorzystaniem analizy skupień. Przegląd Spawalnictwa 12/2014.

[23] Fydrych D., Sommer S., Rogalski G.: Analiza skupień jako metoda wspomagania decyzji zakupu urządzeń prądu stałego do spawania metodą TIG. Logistyka 6/2014.

[24] Szromek A.R., Krajewska-Siuda E.: Koncepcja klasyfikacji diagnostycznej dzieci z niskorosłością i jej ekonomiczne implikacje: ilościowe modele klasyfikacyjne w diagnostyce medycznej. Wydawnictwo Politechniki Śląskiej, Gliwice 2008.

[25] Białek M., Rutkowska J., Wieczorek P., Białek A.: Ocena jakości żywieniowej frakcji tłuszczowej wyrobów cukierniczych typu baton przeznaczonych dla dzieci. Problemy Higieny i Epidemiologii 2/2015.

[26] Chudy-Laskowska K., Wierzbińska M.: Analiza infrastruktury transportowej w Polsce-wyniki badań. Logistyka 3/2011

[27] Młynarczuk M., Ładniak M.: Wykorzystanie metod sztucznej inteligencji do wyszukiwania obrazem wybranych struktur skał. Przegląd Górniczy 3/2014.

[28] Kołodziejczak M.: Typologia krajów Unii Europejskiej ze względu na znaczenie i poziom korzystania $z$ usług weterynaryjnych w rolnictwie. Zeszyty Naukowe Szkoły Głównej Gospodarstwa Wiejskiego w Warszawie. Problemy Rolnictwa Światowego 1/2015 